\title{
Acta
Biochimica
Polonica
}

Vol. 51 No. 3/2004

$703-710$

QUARTERLY

\section{Preliminary studies of phthalocyanine sensitizers incorporated into human leukemia cells from two cell-lines ${ }^{\star}$}

\author{
Krzysztof Wiktorowicz ${ }^{1}$, Justyna Cofta $^{1}$, Alina Dudkowiak ${ }^{2}$, Aneta Waszkowiak ${ }^{2}$ \\ and Danuta Frąckowiak ${ }^{2 凶}$ \\ ${ }^{1}$ Department of Biology and Environmental Sciences, K. Marcinkowski University of Medical \\ Sciences, Poznań, Poland, ${ }^{2}$ Institute of Physics, Poznań University of Technology, Poznań, \\ Poland
}

Received: 26 June, 2003; revised: 13 January, 2004; accepted: 23 April, 2004

Key words: CCRF cells, fluorescence, MOLT 4 cells, phthalocyanine, photodynamic therapy

\begin{abstract}
Three phthalocyanine dyes-sensitizers were incorporated into two types of human T leukemia cells from two cell-lines: CCRF and MOLT 4. The efficiency of the dye incorporation into cells and photochemical properties of stained cells were investigated using fluorescence spectroscopy. The dyes exhibited different properties in each of the two cell-lines. Small differences in cell membrane properties have a strong influence on the efficiency of dye incorporation and on the course of photodynamic reaction. It is suggested that, for a given patient, an optimal dye-sensitizer should be established before photodynamic treatment.
\end{abstract}

Phthalocyanines (Pcs) are promising candidates for medical applications because they show a strong $\mathrm{Q}$ band in the absorption spectrum, located in the red region in which the tissue is rather transparent (Rosenthal et al., 1991; Frackowiak et al., 1998; 2001b; Waszkowiak et al., 2002, Wiktorowicz et al., 2004) and they are fluorescent, which provides an opportunity for the establishment of their localization in the tissue (Pogue et al., 2001; Wood et al., 1997). Therefore, they have already been widely investigated in view of their possible applications in photodynamic therapy (PDT) and photodynamic diagnosis (PDD) (Wood et al., 1997; Cubeddu et al., 2000; Trivedi et al., 2000; Pogue et al., 2001).

\footnotetext{
${ }^{8}$ K.W., J.C., A.D and D.F. thank for financial support from KBN (Poland) Grant 3 P05B 07324 (2003-2005) and A.W. thanks for support by grant DS 62/176 from Poznań University of Technology. ${ }^{\square}$ Corresponding author: Institute of Physics, Poznań University of Technology, Nieszawska 13A, 60-965 Poznań, Poland; phone: (48 61) 665 3180, fax: (48 61) 665 3201; e-mail: frackow@phys.put.poznan.pl
} Abbreviations: Pc, phthalocyanine; PDD, photodynamic diagnosis; PDT, photodynamic therapy. 
Synthetic dyes are still useful for PDT, in addition to the naturally occurring compounds which can be metabolized to photosensitive products (Kelty et al., 2002). Cells activated by mitogens (e.g. phytohemagglutinin), investigated previously (Waszkowiak et al., 2002; Wiktorowicz et al., 2004), are model systems of malignant cells. To be an efficient photosensitizer for PDT, the dye-sensitizer should be (i) efficiently incorporated into malignant cells, (ii) non-toxic for healthy cells, and (iii) exhibit high yield of triplet states generation. The last condition is fulfilled for most of the Pcs investigated by us, which in solutions exhibit different, but always high yield of $\mathrm{S} \rightarrow \mathrm{T}$ intersystem crossing transitions (Frackowiak et al., 2001a). It was shown (Wiktorowicz et $a l ., 2004)$ that the photodynamic reaction in activated cells is very efficient for dyes exhibiting high efficiency of triplet state generation in solutions.

The spectral and photochemical properties of dyes in cells and in solution can be different. Therefore, in this work we established the spectral properties of three Pcs incorporated into leukemia cells from two cell-lines. These dyes, whose structures are presented in Fig. 1, were previously investigated in various model systems (Frąckowiak et al., 2001a; 2001b; 2002; Waszkowiak et al., 2002; Wiktorowicz et al., 2004).

The absorption spectra of stained and unstained cells were not much different even in the region of maximal absorption of the applied dyes (at about $610 \mathrm{~nm}$ ) and were additionally perturbed by light scattering. Therefore, in this preliminary study, the fluorescence spectra were used for monitoring the photoreactions occurring in the cells.

\section{MATERIAL AND METHODS}

Leukemia T cells from two continuous culture lines, obtained from the Institute of Immunology and Experimental Therapy (Polish Academy of Sciences, Wrocław, Poland), were incubated in Pcs solutions. The first line (CCRF) was derived from a Caucasian girl with acute lymphoblastic leukemia (ALL). The membrane properties of these cells were: CD2-, $\mathrm{CD} 3+, \mathrm{CD} 4+, \mathrm{CD} 5+, \mathrm{CD} 6+, \mathrm{CD} 7+$, CD8-, CD13-, CD14-, CD15+, CD19-, CD33-, CD34-, CD68-, CDw90-, HLA-DR-, $\mathrm{TCR} \alpha / \beta+$, TCR $\gamma / \delta-(\mathrm{CD}-$ cluster of differentiation, numbers describe the type of proteins (glycoproteins) in cell membranes; TCR - antigenic receptor of lymphocytes). The morphology of the cells was: round cells growing singly in suspension and as adherent epitheloid cells forming a monolayer. The cells from the second line (MOLT-4) were from a 19 year old man with ALL. These cells exhibit the following characteristics: $\mathrm{CD} 2+$, CD3+, CD4+, CD5+, CD6+, CD7+, CD8+, CD13-, CD19-, CD34+, TCR $\alpha / \beta-$, TCR $\gamma / \delta-$. The morphology of these cells was: round cells growing in suspension singly or in clusters.

The cells were grown in stationary suspension cultures, using standard culture conditions $\left(37^{\circ} \mathrm{C}, 5 \% \mathrm{CO}_{2}\right)$ in RPMI 1640 medium with $2 \mathrm{mM}$ L-glutamine and supplemented with $10 \%$ FBS (fetal bovine serum, Sigma).

The Pcs were purchased from Sigma-Aldrich and used without further purification. The molecular structures of these Pcs and their abbreviated notation are shown in Fig. 1.

Dye solution $\left(10^{-5} \mathrm{M}\right)$ in dimethyl sulfoxide $\left(\mathrm{Me}_{2} \mathrm{SO}\right.$ ) (with $0.5 \% \quad \mathrm{H}_{2} \mathrm{O}$ ) was added to such a volume of cell suspension that $1 \mathrm{ml}$ of final suspension contained $10^{6}$ cells. Incubation was carried out at $(37 \pm 1)^{\circ} \mathrm{C}$ for $1 \mathrm{~h}$ in the dark. Then the stained cells were washed three times and resuspended in $0.9 \% \mathrm{NaCl}$ in $\mathrm{H}_{2} \mathrm{O}$. The cells incubated in pure $\mathrm{Me}_{2} \mathrm{SO}$ (without dye) used as a reference samples were investigated cytometrically. The results show that the number of dead cells in such samples was always lower than $10 \%$.

Samples were illuminated with a He-Ne laser light $\left(\lambda_{\text {las }}=632.8 \mathrm{~nm}\right.$, light intensity 2 $\mathrm{mW} / \mathrm{cm}^{2}$ ) for 1,2 or $3 \mathrm{~h}$. During the illumination the temperature was stable to $\pm 2^{\circ} \mathrm{C}$. The 
a)

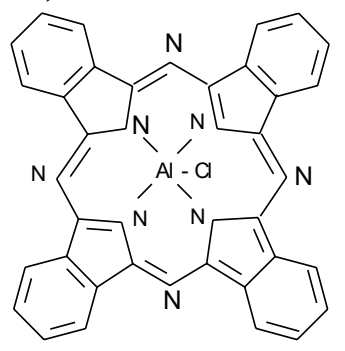

b)

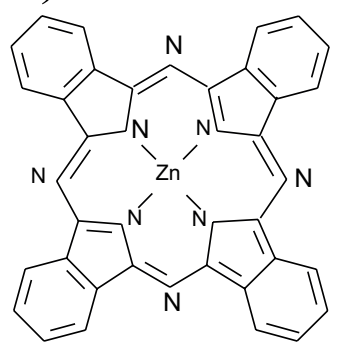

c)

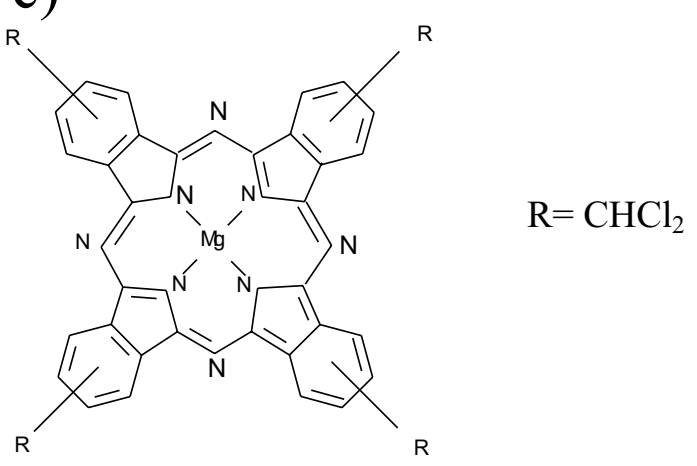

Figure 1. Structures of the investigated phthalocyanines: (a) AlPcCl, (b) ZnPc, (c) MgPc.

dose of light energy delivered during $1 \mathrm{~h}$ was about $7.2 \mathrm{~J} / \mathrm{cm}^{2}$. It was almost 1.5 fold higher than that used in (Pogue et al., 2001) for killing $50 \%$ of cancer cells. The reference sample (non-stained) cells after the same illuminations were also investigated.

Absorption spectra were recorded using a Specord M40 Carl Zeiss (Jena, Germany) spectrophotometer, fluorescence spectra by means of a Hitachi F 4500 (Japan). The width of the spectral band used in excitation and emission beams was $5 \mathrm{~nm}$. Even unstained cells exhibit some autofluorescence of cell material (Frackowiak et al., 1998; Pogue et al., 2001; Monici et al., 2003). The changes in this emission caused by illumination, measured for stained and unstained cells, have been recently used for monitoring the course of photodynamic reactions (Monici et al., 2003). The intensity of fluorescence of a dye incorporated into cells depends on the efficiency of the dye incorporation and on the yield of its fluorescence. The yields of dye fluorescence in various cell-lines can be different because of possible differences in their location in different types of cells, resulting in different interactions of the dye molecule with the surroundings.

Fluorescence was excited in two regions: in the region of the incorporated dye absorption (at $610 \mathrm{~nm}$ ) and in the region of the cell material absorption (at $295 \mathrm{~nm}$ ). The fluorescence of the incorporated dye (measured in the 640-800 $\mathrm{nm}$ range) provided information on the efficiency of the dye incorporation into the cells and on the possible dye bleaching during illumination. The changes in the short wavelength (300-500 nm) endogenous fluorescence of the cell material can be related to changes in cell properties caused by the dye incorporation and by the illumination. From our preliminary results, it is not possible to establish the character of the photochemical or conformational changes occurring in the cell material because in the region of fluorescence excitation contributions from different compounds superimpose.

\section{RESULTS}

The absorption spectra of MOLT 4 cells stained by various Pcs and of the same cells incubated in $\mathrm{Me}_{2} \mathrm{SO}$ without dyes were measured before and after illumination. The illumination caused different changes in the absorption in the 200-250 $\mathrm{nm}$ range for non-stained cells as well as for cells stained by the same dye in a case of cells obtained from 
two cell-lines (not shown). The absorption of the dyes in this region can be neglected. The long wavelength absorption (about 600-700 $\mathrm{nm}$ ) in which the Pcs absorption can be expected (Rosenthal, 1991; Waszkowiak et al., 2002) for the Pc dyes incorporated into cells was very low and perturbed by light scattering (not shown). The changes in the cell material absorption and endogenous cell fluorescence due to the cell staining as well as the fluorescence of the Pcs incorporated into cells showed clearly that the dye molecules were present in the stained cells. The emission of non-stained cells (excited at $610 \mathrm{~nm}$ ) in the longwavelength region was not measurable.

Figure 2 shows the fluorescence excitation spectra of the two types of cells with $\mathrm{AlPcCl}$ incorporated. The changes in the fluorescence at $340 \mathrm{~nm}$ (i.e. in the region of the cell material emission) observed as a result of illumination are different for the cells stained with the same dye but coming from the two lines. Figure 3 presents the fluorescence spectra of the cells stained by the same dye excited and measured in two wavelength regions. The emission of the cell material (excited at $295 \mathrm{~nm}$, measured from 300 to $500 \mathrm{~nm}$ ) and the emission of the cell-incorporated dye (excited at $610 \mathrm{~nm}$, observed from 640 to $800 \mathrm{~nm}$ ) were observed as a function of the time of illumination and shown to be different for the two types of cells. The fluorescence of the dye was less intense than that of the cell material but well measurable. It is known (Frackowiak et al., 2001b; Wiktorowicz et al., 2004) that the Pcs fluorescence yield in the cells is about tenfold lower than in most solvents. The low fluorescence intensity can be observed in the cells, even at a high level of dye incorporation, as established by photothermal spectral measurements (Frackowiak et al., 1998). The higher intensity of $\mathrm{AlPcCl}$ fluorescence in CCRF cells than in MOLT 4 cells may be due to a more efficient incorporation of the dye into the former and/or to a higher yield of the dye fluorescence due to different intracellular location of the dye molecules.

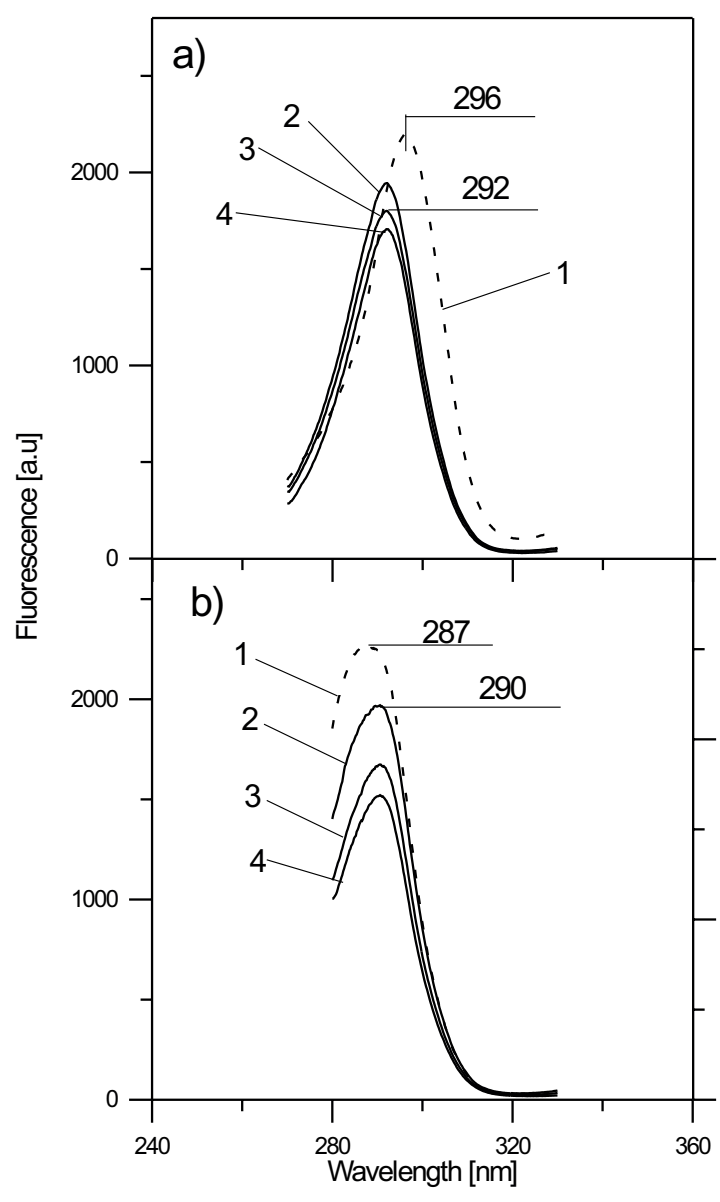

Figure 2. Fluorescence excitation spectra of CCRF (a) and MOLT 4 (b) cells stained by AlPcCl measured, at $340 \mathrm{~nm}$, after illumination for: $0 \mathrm{~h}$ (1), $1 \mathrm{~h}$ (2), $2 \mathrm{~h}$ (3) and $3 \mathrm{~h}$ (4).

Figure 4 presents the changes in the intensities of the main fluorescence bands caused by illumination of the samples incubated with $\mathrm{AlPcCl}, \mathrm{ZnPc}$ and $\mathrm{MgPc}$, in comparison with the changes observed for unstained cells. The endogenous cell fluorescence can be related to several compounds (tryptophan, flavins, nicotinamide adenine dinucleotide) (Anderson-Engels et al., 1991; Pogue et al., 2001; Waszkowiak et al., 2002; Monici et al., 2003). Using only one wavelength of excitation (in fluorescence spectra) and one region of emission observation (in excitation spectra) it is not possible to establish the contributions from all sources.

The fluorescence intensity of stained non-illuminated cells depends on the volume of the cells in the sample, the efficiency of the dye incorporation and the perturbation in the cell 

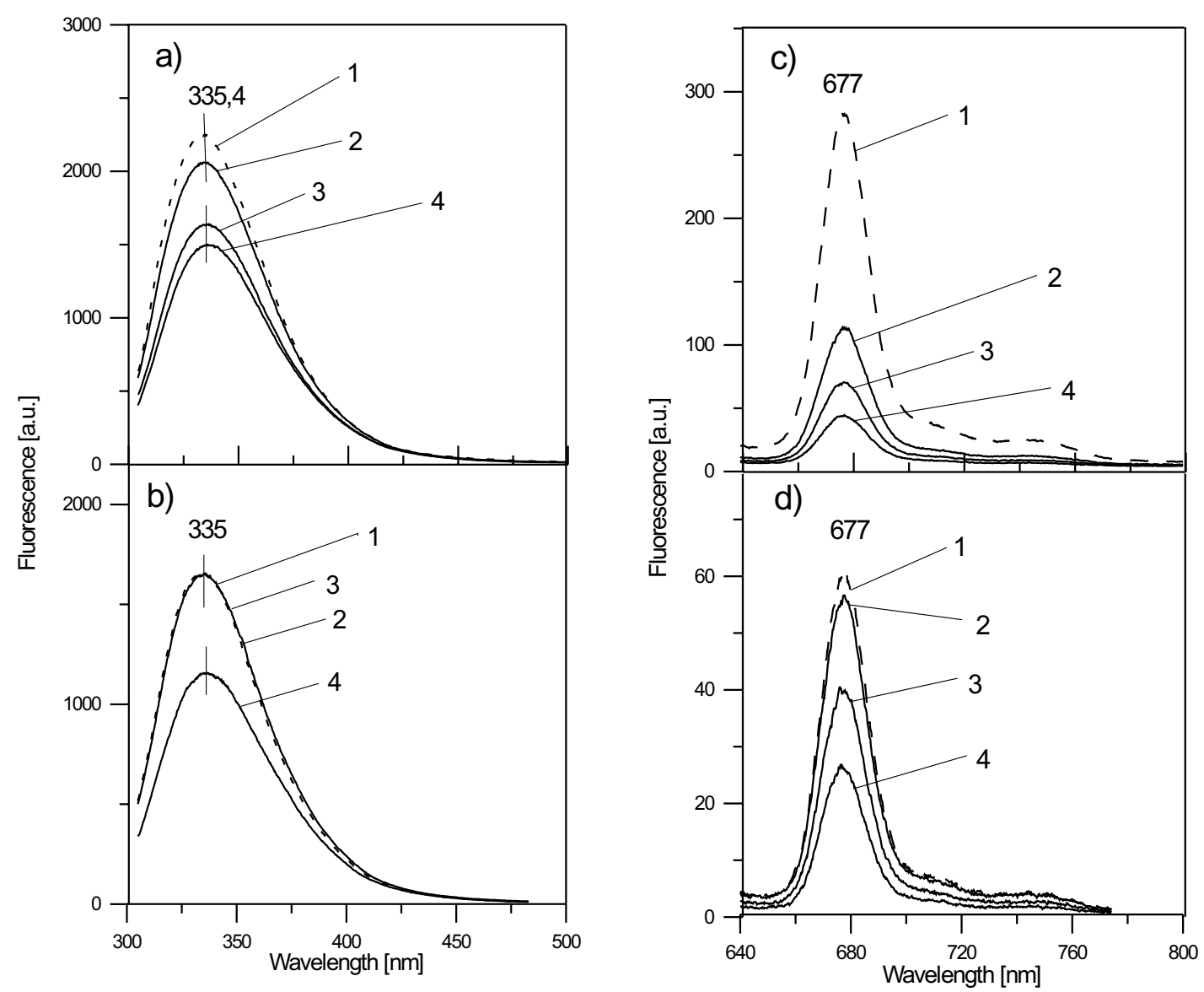

Figure 3. Fluorescence spectra excited at $295 \mathrm{~nm}(\mathrm{a}, \mathrm{b})$ and at $610 \mathrm{~nm}$ (c, d) for the CCRF (a, c) and MOLT 4 (b, d) leukemia cells stained by AlPcCl, illuminated for: 0 h (1), 1 h (2), 2 h (3), 3 h (4).

caused by the incorporation of dye molecules. To eliminate these unknown effects, in Fig. 4 the fluorescence intensities of non-illuminated cells of every type are normalized, and the kinetics of photoreactions are shown as changes in the emission intensity.

As it follows from Fig. 4, the effect of illumination is different in non-stained and stained cells and is different for various Pcs introduced, but always depends strongly on the type of the cells. The photosensitivity of unstained cells from the two lines is different (Fig. $4 \mathrm{a}, \mathrm{b}$ ). Also the photodestruction of a dye depends on the cell line (Fig. 4 c, d). For cells stained by some dyes the changes in cell material emission are in some cases lower than for unstained cells (Fig. 4 b). The significant changes as a result of illumination observed for the cells from the two lines suggest different modifications of the cell structure or/and different photochemical sensitivity of the samples.

\section{DISCUSSION}

The modes of interactions of dye photosensitizers with lipids and proteins are different. It is known (Schafer et al., 1999) that singlet oxygen ${ }^{1} \mathrm{O}_{2}$ generated by exited Photofrin is quenched by lipids only by a chemical mechanism, while proteins quench it by chemical or physical mechanisms. Dye and illumination affect membrane permeability of leukemia cells. This effect differs for cells from various lines (Schafer et al., 1999). The damage to the membranes depends on the types and amounts of lipid and proteins in the cells. Therefore, it is different for cells from various lines. It seems that proteins can 

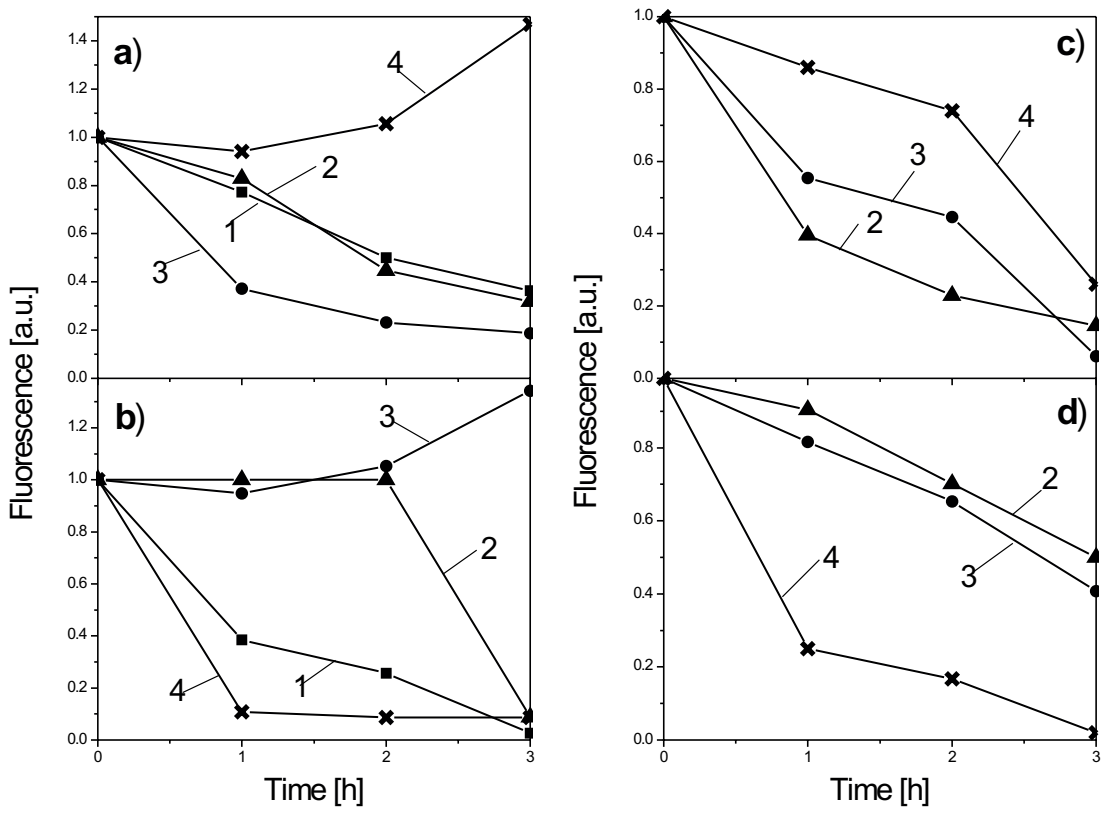

Figure 4. Dependence of intensities at main fluorescence band as a function of illumination time.

Cells obtained from CCRF (a, c) and MOLT 4 (b, d) cell lines. Unstained cells (curves 1); cells stained by AlPcCl (curves 2), $\mathrm{ZnPc}$ (curves 3) and MgPc (curves 4). Wavelengths of fluorescence excitation $\left(\lambda_{\text {exc }}\right.$ ) and observation $\left(\lambda_{\text {obs }}\right)$ : in the case of cell material emission ( $\left.\mathrm{a}, \mathrm{b}\right) \lambda_{\mathrm{exc}}=295 \mathrm{~nm}$ and $\lambda_{\mathrm{obs}}=335 \mathrm{~nm}$; in the case of dye emission (c, d): $\lambda_{\text {exc }}=610 \mathrm{~nm}$ and $\lambda_{\text {obs }}=667 \mathrm{~nm}$ for AlPcCl, $\lambda_{\text {obs }}=674 \mathrm{~nm}$ for $\mathrm{ZnPc}, \lambda_{\text {obs }}=675 \mathrm{~nm}$ for MgPc.

protect leukemia cells against the damage caused by photosensitizers and illumination by quenching singlet oxygen. Larger cells are better protected than smaller ones (Schafer et $a l ., 1999)$. The sizes of the cells studied in this work are rather similar. The experiments showed that the kinetics of the photoreactions in stained cells from the two lines are different and that these differences are dependent on the dye used. The cell size can influence the course of photoreactions (Schafer et al., 1999), but this factor cannot explain the different behavior of various Pcs. There are still several open questions and they will be the subject of further investigations. We plan to extend the investigation to several cell-lines and more dyes. The establishment of the precise localization of the dye molecules in cell structures is very important (Cubeddu et al., 2000; Pogue et al., s24 2001; Monici et al., 2003). It is known that Pcs engaged in different interactions with the sur- roundings have different spectral properties (Frackowiak et al., 2002). The different photochemical properties of various Pcs in the cells suggest that they interact with different macromolecules, because in solutions all these dyes exhibit similar high yields of triplet states generation (Frackowiak et al., 2001a).

Triplet states of investigated Pcs in solutions are to a similar degree quenched by oxygen (Frackowiak et al., 2001a). Therefore, one can predict that these dyes will have a similar photochemical sensitivity. We found out (Frackowiak et al., 2002) that the Pcs with the same central metal ion and different side groups can be ordered differently with respect to polymer chains. A similar situation can occur in the cell material where these dyes can differently interact with macromolecules because of their various orientation. This corresponds to the data reported by Feofanov et al. (2002) that Pcs with the same 
central metal and different side groups can exhibit different activity in PDT. It is known (Langlois et al., 1986) that some Pcs are able to oxidize tryptophan and cholesterol. Further studies are necessary in order to establish if after illumination the observed spectral changes in cell material are due to photochemical or to conformational changes.

On the basis of the current knowledge of the mechanisms of interaction between Pcs and cell material, it is not easy to predict the efficiency of anti-tumor activity of a given $\mathrm{Pc}$ in the patient cells. Therefore, it seems that it would be practical to work out a simple test providing information about the interaction of patient cells with the photosensitizer.

The presented results show that small differences in the properties of leukemia $\mathrm{T}$ cells cause significant differences in the yield of the dye incorporation as well as in the course of the photoreactions occurring in the stained illuminated cells. Different dyes are optimal photosensitizers for various cell-lines. It is not easy to find the dye which can be an optimal sensitizer for all types of the cells. This suggests that before PDT treatment the interaction of a dye with the patient's cells should be investigated. Working out a simple test to the above effect will be our future task.

The authors would like to express their sincere appreciation to Professor Danuta Duś from the Ludwik Hirszfeld Institute of Immunology and Experimental Therapy (Wrocław, Poland) for her help with managing the cell tissue culture.

\section{R E F E R E N C E S}

Anderson-Engels S, Johansson J, Svanberg K, Svanberg S. (1991) Fluorescence imaging and point measurements of tissue: Applications to the demarcation of malignant tumors and atherosclerotic lesions from normal tissue. Photochem Photobiol.; 53: $807-14$
Cubeddu R, Petteri A, Taroni R, Toricelli A, Valentini G, Comelli D, D'Andrea C, Angelini V, Conti G. (2000) Fluorescence imaging during photodynamic therapy of experimental tumors in mice sensitized with disulfonated aluminium phthalocyanine. Photochem Photobiol.; 72: 690-5.

Feofanov A, Grichine A, Karmakova T, Kazachkina N, Pecherskih E, Yakubovskaya R, Luk'yanets E, Derkacheva V, Egret-Charlier M, Vigny P. (2002) Chelation with metal is not essential for antitumor photodynamic activity of sulfonated phthalocyanines. Photochem Photobiol.; 75: $527-33$.

Frąckowiak D, Ion RM, Waszkowiak A. (2002) Spectral properties of phthalocyanines in stretched polymer films. $J$ Phys Chem. B; 106: $13154-60$.

Frąckowiak D, Planner A, Ion RM, Wiktorowicz K. (1998) Incorporation of dye in resting and stimulated leukocytes. In Near-infrared dyes for high technology applications. Daehne $\mathrm{S}$, Resch-Gennger U, Wolfbais OA. eds, pp 87-114. Kluwer Academic Press.

Frąckowiak D, Planner A, Waszkowiak A, Boguta A, Ion RM, Wiktorowicz K. (2001a) Yield of phthalocyanines intersystem (sin glet $\rightarrow$ triplet) crossing evaluated on the basis of time-resolved photothermal method. $J$ Photochem Photobiol. A: Chem.; 141: 101-8.

Frackkowiak D, Waszkowiak A, Manikowski H, Ion RM, Wiktorowicz K. (2001b) The interactions of phthalocyanines with stimulated and resting human peripherical blood mononuclear cells. Acta Biochim Polon.; 48: 257-69.

Kelty CJ, Brown NJ, Reed MWR, Ackroyd R. (2002) The use of 5-aminoevulinic acid as a photosensitizer in photodynamic therapy and photodiagnosis. Photochem Photobiol Sci.; 1: 158-64.

Langlois R, Ali H, Brasseur N, Wagner JR, van Lier JE. (1986) Biological activities of phthalocyanines - IV. Type II sensitized photooxidation of L-tryptophan and cholesterol by sulfonated metallo phthalocyanines. Photochem Photobiol.; 44: 117-23. 
Monici M, Agati G, Fusi F, Pratesi R, Paglierani M, Santini V, Bernabei PA. (2003) Dependence of leukemic cell autofluorescence patterns on the degree of differentiation. Photochem Photobiol Sci.; 2: 981-7.

Pogue BW, Pitts ID, Mycek AM, Sloboda RD, Wilmot CM, Brandsema JF, O'Hara JA. (2001) In vivo NADH fluorescence monitoring as an assay for cellular damage in photodynamic therapy. Photochem Photobiol.; 74: 817-24.

Rosenthal I. (1991) Phthalocyanines as photodynamic sensitizers. Photochem Photobiol.; 53: 859-70.

Schafer FQ, Buettner RG. (1999) Singlet oxygen toxicity in cell lines-dependent: A study of lipid peroxidation in nine leukemia cell lines. Photochem Photobiol.; 70: 858-67.

Trivedi N, Wang HW, Nieminen AL, Oleinick NL, Izatt JA. (2000) Quantitative analysis of
PCU localization in mouse lyphoma (LY-R) cells via double-label confocal fluorescence microscopy. Photochem Photobiol.; 71:

634-9.

Waszkowiak A, Frąckowiak D, Wiktorowicz K, Miyake J. (2002) Spectral properties of phthalocyanines incorporated in resting and stimulated human peripherical blood cells. Acta Biochim Polon.; 49: 633-41.

Wiktorowicz K, Waszkowiak A, Cofta J, Frąckowiak D. (2004) The kinetics of photoreactions occurring in resting and stimulated lymphocytes stained by two phthalocyanines exhibiting various efficiencies of triplet state generation. Current Topics Biophys. (in press).

Wood SR, Holroyd IA, Brown SB. (1997) The subcellular localization of Zn (II) phthalocyanines and their redistribution on exposure to light. Photochem Photobiol.; 65: 397-402. 